Author affiliations appear at the end of this article.

Published online ahead of print at www.jco.org on July 11, 2016

Supported by the Global Spine Tumour Study Group, a registered charity of England and Wales, Charity Commission number 1134934 , and DePuy Synthes. This study was performed in part at University College London Biomedical Research Centre, which receives funding from the National Institute for Health Research.

Authors' disclosures of potential conflicts of interest are found in the article online at www.jco.org. Author contributions are found at the end of this article.

Corresponding author: Jorrit-Jan Verlaan, MD, PhD, University Medical Center Utrecht, Room G.05.228, Heidelberglaan 100, 3584CX, Utrecht, the Netherlands e-mail: j.j.verlaan@umcutrecht.nl.

(C) 2016 by American Society of Clinical Oncology

0732-183X/16/3425w-3054w/\$20.00

DOI: $10.1200 / J C O .2015 .65 .1497$

\title{
Characteristics of Patients Who Survived $<3$ Months or $>2$ Years After Surgery for Spinal Metastases: Can We Avoid Inappropriate Patient Selection?
}

Jorrit-Jan Verlaan, David Choi, Anne Versteeg, Todd Albert, Mark Arts, Laurent Balabaud, Cody Bunger, Jacob Maciej Buchowski, Chung Kee Chung, Maarten Hubert Coppes, Hugh Alan Crockard, Bart Depreitere, Michael George Fehlings, James Harrop, Norio Kawahara, Eun Sang Kim, Chong-Suh Lee, Yee Leung, Zhongjun Liu, Antonio Martin-Benlloch, Eric Maurice Massicotte, Christian Mazel, Bernhard Meyer, Wilco Peul, Nasir A. Quraishi, Yasuaki Tokuhashi, Katsuro Tomita, Christian Ulbricht, Michael Wang, and F. Cumhur Oner

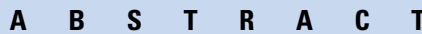

\section{Purpose}

Survival after metastatic cancer has improved at the cost of increased presentation with metastatic spinal disease. For patients with pathologic spinal fractures and/or spinal cord compression, surgical intervention may relieve pain and improve quality of life. Surgery is generally considered to be inappropriate if anticipated survival is $<3$ months. The aim of this international multicenter study was to analyze data from patients who died within 3 months or 2 years after surgery, to identify preoperative factors associated with poor or good survival, and to avoid inappropriate selection of patients for surgery in the future.

\section{Patients and Methods}

A total of 1,266 patients underwent surgery for impending pathologic fractures and/or neurologic deficits and were prospectively observed. Data collected included tumor characteristics, preoperative fitness (American Society of Anesthesiologists advisory [ASA]), neurologic status (Frankel scale), performance (Karnofsky performance score [KPS]), and quality of life (EuroQol five-dimensions questionnaire [EQ-5D]). Outcomes were survival at 3 months and 2 years postsurgery. Univariable and multivariable logistic regression analyses were used to find preoperative factors associated with short-term and long-term survival.

\section{Results}

In univariable analysis, age, emergency surgery, KPS, EQ-5D, ASA, Frankel, and Tokuhashi/Tomita scores were significantly associated with short survival. In multivariable analysis, KPS and age were significantly associated with short survival (odds ratio [OR], 1.36; 95\% Cl, 1.15 to 1.62; and OR, 1.14; $95 \% \mathrm{Cl}, 1.02$ to 1.27 , respectively). Associated with longer survival in univariable analysis were age, number of levels included in surgery, KPS, EQ-5D, Frankel, and Tokuhashi/Tomita scores. In multivariable analysis, the number of levels included in surgery (OR, 1.21; $95 \% \mathrm{Cl}, 1.06$ to 1.38 ) and primary tumor type were significantly associated with longer survival.

\section{Conclusion}

Poor performance status at presentation is the strongest indicator of poor short-term survival, whereas low disease load and favorable tumor histology are associated with longer-term survival.

\section{J Clin Oncol 34:3054-3061. (C) 2016 by American Society of Clinical Oncology}

\section{INTRODUCTION}

Because of improvements in systemic therapy, survival of patients with metastasized cancer has improved substantially in the past decade. ${ }^{1}$ As a result, the number of patients with symptomatic spinal metastases is increasing, which necessitates the development of new strategies to improve the quality of the remaining lifespan for individual patients. ${ }^{2}$ Currently, painful spinal metastases without signs of gross mechanical instability or spinal cord compression can usually be treated successfully with external beam irradiation. ${ }^{3}$ With increasing mechanical instability or in the presence of pathologic fractures and/or symptomatic 
spinal cord compression, surgical intervention may be warranted to provide mechanical stability and/or to decompress neural structures. 4

In general, spine surgeons select less-demanding interventions for patients with limited life expectancy and save larger interventions for patients with relatively good prognosis. ${ }^{5,6}$ After the introduction of less-invasive techniques, minimum life expectancy required for patients to benefit from surgery has decreased as time to recovery and surgical demand is reduced. ${ }^{7}$ Now, spine surgeons may perform palliative surgery with the goal of increasing quality of life, provided the patient has a reasonable chance to survive for at least 3 months. ${ }^{8}$ Patients with life expectancies $<3$ months are generally regarded as unsuitable for surgery as the risks and drawbacks, including pre- and postoperative complications, managing postoperative pain, and time required for recovery, are considered to outweigh the benefits of intervention, and patients are subsequently referred for radiotherapy or palliative medical care. ${ }^{5,8,9}$ Similarly, patients who undergo highly demanding surgery need a sufficiently large life expectancy to recover and to benefit from these larger procedures. Because of a lack of solid selection criteria, surgeons currently rely mainly on subjective clinical and radiologic assessments to determine the extent of surgery deemed appropriate. The number of patients who do not receive optimal surgical care as a result of under- or overtreatment is not known; therefore, it would be valuable to identify preoperative factors associated with exceedingly short survival to learn which patients may not benefit from surgery and to also identify factors associated with prolonged survival to help select patients who will potentially

\begin{tabular}{|c|c|}
\hline Parameter & Definition \\
\hline Age at surgery & Years \\
\hline Gender & Male and female \\
\hline Surgical priority & $\begin{array}{l}\text { Emergency ( }<1 \text { day), urgent } \\
\quad(1-3 \text { days), scheduled ( }>3 \text { days) }\end{array}$ \\
\hline Spinal levels affected & No. of levels \\
\hline Karnofsky performance score & Scale of $0-100$ \\
\hline EQ-5D index & $\begin{array}{l}\text { EuroQol five-dimensions } \\
\text { questionnaire }\end{array}$ \\
\hline Frankel category & Frankel grading system (A/B/C/D/E) \\
\hline Tokuhashi score & $0-15$ points \\
\hline Tomita score & 2-10 points \\
\hline Paralysis $=$ yes & Wheelchair bound or confined to bed \\
\hline ASA score & $\begin{array}{l}\text { American Society for } \\
\text { Anesthesiologists score (1-4) }\end{array}$ \\
\hline Histologic tumor diagnosis & $\begin{array}{l}\text { Breast, colorectal, renal, lung, } \\
\text { prostate, myeloma, gastric, liver, } \\
\text { bladder, lymphoma, melanoma, } \\
\text { sarcoma, thyroid, miscellaneous }\end{array}$ \\
\hline $\begin{array}{l}\text { No. of extraspinal metastasis } \\
\text { locations }\end{array}$ & $0-4$ \\
\hline Preoperative pain level & Numeric rating scale $(0-10)$ \\
\hline Intraoperative complications & Vascular; neurologic; visceral \\
\hline $\begin{array}{l}\text { Postoperative complications, } \\
\text { including directly related to surgical } \\
\text { intervention }\end{array}$ & $\begin{array}{l}\text { Hematoma, infection, implant failure, } \\
\text { CSF leakage, wound breakdown, } \\
\text { neurologic deterioration, other }\end{array}$ \\
\hline Cause of death & $\begin{array}{l}\text { Related to disease, unrelated to } \\
\text { disease, related to spine treatment, } \\
\text { related to spine surgery, other/not } \\
\text { known }\end{array}$ \\
\hline
\end{tabular}
with surgically treated symptomatic spinal metastases were consecutively included in 23 internationally recognized spine centers. Indications for surgery were back pain caused by mechanical instability and/or neurologic symptoms as assessed by the treating spine surgeon and according to institutional practices and guidelines. ${ }^{10}$ All principal investigators adhered to the principle that to perform any type of spine surgery, life expectancy for individual patients should be no less than 3 months as established by the treating oncologist. Participating centers were located in Belgium, Canada, People's Republic of China, Denmark, France, Germany, Japan, the Netherlands, Spain, South Korea, the United Kingdom, and the United States. All centers collected predefined parameters prospectively and entered anonymized data via a secure internet database. ${ }^{10,11}$ Institutional review board approval was obtained for all centers following local regulations. Data collection started in March 2001 and continued until October 2014 when the database was closed for data analysis to answer our specific research questions. Anonymous case records were kept for individual patients and included detailed information on primary tumor histology, oncologic treatment received previously, preoperative characteristics, and surgical, discharge, and follow-up data. Although patients with multiple myeloma can be regarded as a distinct category, they were included because of similarity in management. Patients were observed from enrollment up to 2 years after surgery or death. Table 1 gives a detailed listing of collected parameters. Primary outcome was survival at 3 months postsurgery and secondary outcome was survival at 2 years postsurgery. To ensure reliability of primary and secondary outcomes, participating investigators reviewed all their case records after closure of the database with special emphasis on vital statistics—being dead or alive—for each patient.

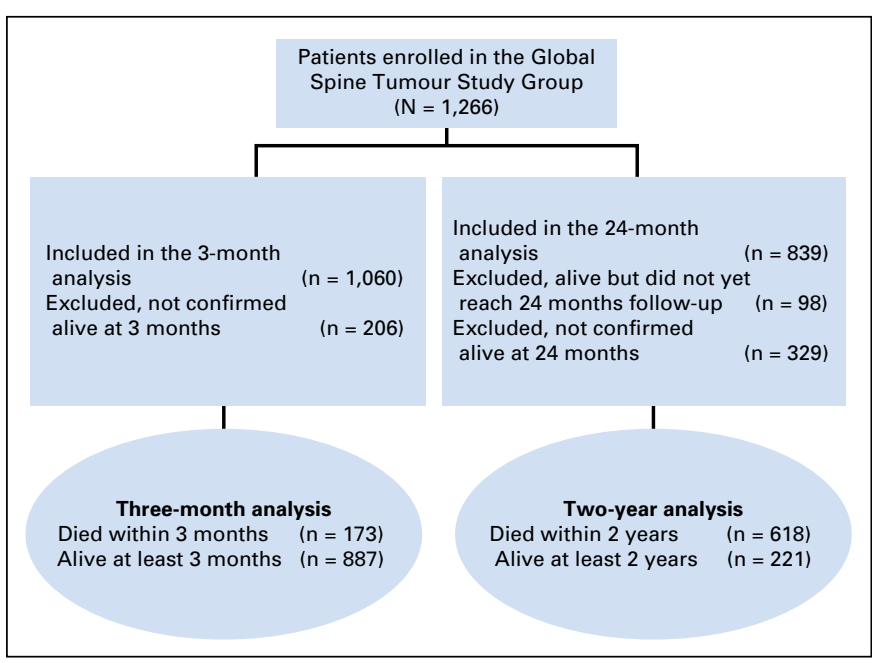

Fig 1. CONSORT diagram. 


\section{Statistical Analysis}

Data distributions were reviewed before analysis of results and calculations of statistical parameters. Univariable and multivariable logistic regression analyses of cases without missing data were performed to assess factors associated with dying within 3 months after surgery and factors associated with survival after surgery for $>2$ years. Pertinent variables-considered directly relevant to the outcome but not obviously interrelated or similar to other variables-were included in multivariable analysis if observed at least 400 times. Sensitivity analyses were performed to test the influence of missing values on results. $P$ values $<.05$ were considered significant. All statistical tests were performed with Stata
13.1 software (STATA, College Station, TX; Computing Resource Center, Santa Monica, CA).

\section{RESULTS}

A total of 1,266 patients were included in the database. The cohort used in the analysis is under ongoing follow-up. Of 1,266 patients, 1,060 patients have been observed past 3 months or have died within this period; 839 have been observed past 2 years or have died

\begin{tabular}{|c|c|c|c|c|}
\hline Characteristic & Observed No. & Overall $(\mathrm{N}=1,266)$ & Alive $(n=648)$ & Died $(n=618)$ \\
\hline Age at surgery, mean (SD), years & 1,266 & $60.7(12.3)$ & $59.6(12.5)$ & $61.8(11.9)$ \\
\hline Male, No. (\%) & 1,261 & 715 (56.5) & 349 (53.9) & $366(59.2)$ \\
\hline First surgery type, No. (\%) & 941 & & & \\
\hline Emergency & & $163(17.3)$ & $76(14.2)$ & 87 (21.4) \\
\hline Scheduled & & $484(51.4)$ & 297 (55.6) & $187(46.0)$ \\
\hline Urgent & & $294(31.2)$ & $161(30.2)$ & 133 (32.7) \\
\hline Spinal levels affected, median (IQR) & 1,266 & $1(1-3)$ & $1(1-3)$ & $2(1-3)$ \\
\hline Preoperative KPS score, mean (SD) & 1,000 & $60.2(20.5)$ & $65.0(20.5)$ & $55.6(19.4)$ \\
\hline Preoperative EQ-5D, median (IQR) & 902 & $0.38(0.16-0.69)$ & $0.44(0.20-0.71)$ & $0.31(0.12-0.60)$ \\
\hline Preoperative Frankel category, No. (\%) & 1,239 & & & \\
\hline$A / B / C$ & & $314(25.3)$ & $128(20.0)$ & $186(31.0)$ \\
\hline D & & $432(34.9)$ & 217 (33.9) & $215(35.8)$ \\
\hline E & & 494 (39.8) & $295(46.1)$ & $199(33.2)$ \\
\hline Tokuhashi score, No. (\%) & 877 & & & \\
\hline $0-8$ & & $380(43.0)$ & $166(33.2)$ & $214(55.9)$ \\
\hline $9-11$ & & 351 (39.8) & 219 (43.8) & 132 (34.5) \\
\hline $12-15$ & & $152(17.3)$ & $115(23.0)$ & $37(9.7)$ \\
\hline Tomita score, No. (\%) & 1,110 & & & \\
\hline$\leq 3$ & & $373(33.6)$ & $260(44.1)$ & $113(21.7)$ \\
\hline $4 / 5$ & & $249(22.4)$ & $144(24.4)$ & $105(20.1)$ \\
\hline $6 / 7$ & & $252(22.7)$ & $119(20.2)$ & $133(25.5)$ \\
\hline$\geq 8$ & & $238(21.4)$ & 67 (11.4) & $171(32.8)$ \\
\hline Paralysis, yes, No. (\%) & 1,266 & $352(27.8)$ & $143(22.1)$ & 209 (33.8) \\
\hline ASA, No. (\%) & 1,031 & & & \\
\hline 1 & & $123(11.9)$ & 91 (15.9) & $32(7.0)$ \\
\hline 2 & & $457(44.3)$ & $275(48.0)$ & 182 (39.7) \\
\hline 3 & & $403(39.1)$ & $195(34.0)$ & $208(45.4)$ \\
\hline 4 & & $48(4.7)$ & $12(2.1)$ & $36(7.9)$ \\
\hline \multicolumn{5}{|l|}{ Metastatic tumor diagnosis, No. (\%) } \\
\hline Breast & & $234(18.5)$ & $148(22.8)$ & $86(13.9)$ \\
\hline Colorectal & & $54(4.3)$ & $15(2.3)$ & $39(6.3)$ \\
\hline Renal & & $163(12.9)$ & $88(13.6)$ & $75(12.1)$ \\
\hline Lung (any) & & $163(12.9)$ & $67(10.3)$ & $96(15.5)$ \\
\hline Prostate & & $168(13.3)$ & $67(10.3)$ & $101(16.3)$ \\
\hline Myeloma & & $85(6.7)$ & $66(10.2)$ & $19(3.1)$ \\
\hline Gastric & & $18(1.4)$ & $3(0.5)$ & $15(2.4)$ \\
\hline Liver & & $21(1.7)$ & $9(1.4)$ & $12(1.9)$ \\
\hline Bladder & & $15(1.2)$ & $3(0.5)$ & $12(1.9)$ \\
\hline Lymphoma & & $21(1.7)$ & $17(2.6)$ & $4(0.7)$ \\
\hline Melanoma & & $27(2.1)$ & $15(2.3)$ & $12(1.9)$ \\
\hline Sarcoma & & $18(1.4)$ & $7(1.1)$ & $11(1.8)$ \\
\hline Thyroid & & $37(2.9)$ & $24(3.7)$ & $13(2.1)$ \\
\hline Other specified & & $59(4.7)$ & $25(3.9)$ & $34(5.5)$ \\
\hline Other unknown & & $183(14.5)$ & $94(14.5)$ & $89(14.4)$ \\
\hline Metastasis locations, №. (\%) & 1,266 & & & \\
\hline 0 & & 891 (70.4) & 495 (76.4) & $396(64.1)$ \\
\hline 1 & & $228(18.0)$ & 109 (16.8) & 119 (19.3) \\
\hline 2 & & $102(8.1)$ & $31(4.8)$ & 71 (11.5) \\
\hline 3 & & 39 (3.1) & $12(1.9)$ & 27 (4.4) \\
\hline 4 & & $6(0.5)$ & $1(0.2)$ & $5(0.8)$ \\
\hline
\end{tabular}


in this period (Fig 1). Univariable and multivariable regression analyses are exclusively run on these two, smaller groups. Average age of the patients at time of surgery was $60.7 \pm 12.3$ years and $56.5 \%$ of the population was male. Surgical interventions were performed on a scheduled basis in $51.4 \%$ and urgent or emergency basis in $48.6 \%$ of patients. The five most frequent histologic tumor types were (in order): cancer of the breast, unknown primary, prostate, kidney, and lung. Mean preoperative Karnofsky performance score (KPS) was 60.2 \pm 20.5 . Neurologic status was normal (Frankel E) in 39.8\%, mildly impaired (Frankel D) in $34.9 \%$, and grossly impaired (Frankel C/B/A) in $25.3 \%$ of patients. Median number of spinal levels that warranted surgical intervention was one. The majority of surgical procedures $(84.4 \%)$ were performed intralesionally, which reflected the predominantly palliative character of the intervention. Table 2 gives a detailed listing of baseline characteristics of all patients.

\section{Patients Who Survived < 3 Months}

Descriptive analysis of the group of survivors at 3 months versus those who had died at that point showed that patients who had died within 3 months were in a significantly worse condition preoperatively with more emergency cases, lower preoperative KPS, lower preoperative EQ-5D, more severe neurologic deficits, worse Tokuhashi and Tomita categorical scores, worse ASA scores, and more often presented with unfavorable tumor histology and extraspinal and visceral metastases. Table 3 displays detailed descriptive analysis of the two groups of patients at 3 months postsurgery.

Comparison of characteristics from patients who had a follow-up visit at, at least, 3 months or were discharged at this point $(n=887)$ with those who had died by 3 months $(n=173)$ demonstrated the following factors associated with dying within 3 months in univariable analysis: age per 5-year increase (odds ratio $[\mathrm{OR}], 1.12 ; 95 \% \mathrm{CI}, 1.04$ to $1.20 ; P=.001$ ), emergency surgery (OR, 2.06; 95\% CI, 1.34 to $3.17 ; P=.002$ ), preoperative KPS per 10 -unit decrease (OR, 1.51; 95\% CI, 1.36 to 1.67 ; $P<.001$ ), preoperative EQ-5D per unit decrease (OR, 7.47; 95\% CI, 3.77 to $14.79 ; P<.001)$, and preoperative ASA, Frankel, and Tokuhashi and Tomita categorical scores. Table 4 gives a detailed overview of these factors. In multivariable analysis, however, preoperative KPS per 10-unit decrease and age were the only significant factors associated with dying within 3 months (OR, 1.36; $95 \%$ CI, 1.15 to $1.62 ; P<.001$; and OR, 1.14 ; $95 \%$ CI, 1.02 to $1.27 ; P=.02$, respectively). Appendix Figure A1 (online only) presents a graphical representation of 3-month survival stratified by preoperative KPS. Causes of death for the 173 patients who died within 3 months were systemic progression of cancer $(n=146$; $84.4 \%$ ), a result of complications of spine surgery within 30 days of surgery $(n=7 ; 4.0 \%)$, and not known or not specified $(n=20$; $11.6 \%)$.

\section{Patients Who Survived $>2$ Years}

Descriptive analysis for patients who survived $>2$ years postsurgery compared with those who had died by 2 years after surgery showed survivors to have a favorable preoperative condition with lower age, better preoperative KPS and EQ-5D scores, less (and less severe) neurologic deficits, better ASA, Frankel, and

\begin{tabular}{|c|c|c|c|}
\hline Variable & $\begin{array}{c}\text { Alive } \\
(n=887)\end{array}$ & $\begin{array}{c}\text { Died } \\
(n=173)\end{array}$ & $P$ \\
\hline $\begin{array}{l}\text { Age at surgery, mean (SD), } \\
\text { years }\end{array}$ & $60.0(12.3)$ & $63.3(11.3)$ & .001 \\
\hline Male, No. (\%) & $491(55.4)$ & $116(67.1)$ & .004 \\
\hline First surgery type, No. (\%) & & & $<.001$ \\
\hline Emergency & $109(17.2)$ & $38(29.9)$ & \\
\hline Scheduled & $349(55.0)$ & $47(37.0)$ & \\
\hline Urgent & 177 (27.9) & $42(33.1)$ & \\
\hline Preoperative KPS, mean (SD) & $62.3(20.4)$ & $47.6(16.9)$ & $<.001$ \\
\hline $\begin{array}{l}\text { Preoperative EQ-5D, median } \\
\text { (IQR) }\end{array}$ & $0.44(0.20-0.70)$ & $0.18(0.06-0.44)$ & .001 \\
\hline $\begin{array}{l}\text { Preoperative Frankel } \\
\text { category, No. (\%) }\end{array}$ & & & $<.001$ \\
\hline $\mathrm{A} / \mathrm{B} / \mathrm{C}$ & $188(21.6)$ & 72 (42.9) & \\
\hline D & $301(34.6)$ & $60(35.7)$ & \\
\hline E & $381(43.8)$ & 36 (21.4) & \\
\hline Tokuhashi score, No. (\%) & & & $<.001$ \\
\hline $0-8$ & 232 (39.3) & $82(66.1)$ & \\
\hline $9-11$ & $241(40.8)$ & $38(30.7)$ & \\
\hline $12-15$ & $118(20.0)$ & $4(3.2)$ & \\
\hline Tomita score, No. (\%) & & & $<.001$ \\
\hline$\leq 3$ & 291 (36.6) & $21(15.0)$ & \\
\hline $4 / 5$ & $183(23.0)$ & $19(13.6)$ & \\
\hline $6 / 7$ & 169 (21.3) & 41 (29.3) & \\
\hline$\geq 8$ & $152(19.1)$ & $59(42.1)$ & \\
\hline Paralysis, yes, №. (\%) & 217 (24.5) & $85(49.1)$ & $<.001$ \\
\hline ASA, No. (\%) & & & .007 \\
\hline 1 & $91(12.6)$ & $7(5.4)$ & \\
\hline 2 & 305 (42.3) & $48(37.2)$ & \\
\hline 3 & $293(40.6)$ & $62(48.1)$ & \\
\hline 4 & $32(4.4)$ & $12(9.3)$ & \\
\hline $\begin{array}{c}\text { Intraoperative complications, } \\
\text { yes, No. (\%) }\end{array}$ & $63(7.1)$ & $11(6.4)$ & .73 \\
\hline $\begin{array}{l}\text { Surgical complications, yes, } \\
\text { No. }(\%)\end{array}$ & $149(19.2)$ & 49 (30.6) & .001 \\
\hline $\begin{array}{l}\text { Metastatic tumor diagnosis, } \\
\text { No. (\%) }\end{array}$ & & & $<.001$ \\
\hline Breast & $183(20.6)$ & $14(8.1)$ & \\
\hline Colorectal & $37(4.2)$ & $11(6.4)$ & \\
\hline Renal & $115(13.0)$ & $18(10.4)$ & \\
\hline Lung (any) & $108(12.2)$ & $31(17.9)$ & \\
\hline Prostate & 114 (12.9) & 35 (20.2) & \\
\hline Myeloma & $59(6.7)$ & $7(4.1)$ & \\
\hline Gastric & $14(1.6)$ & $4(2.3)$ & \\
\hline Liver & $14(1.6)$ & $3(1.7)$ & \\
\hline Bladder & $6(0.7)$ & $7(4.1)$ & \\
\hline Lymphoma & $13(1.5)$ & $1(0.6)$ & \\
\hline Melanoma & $19(2.1)$ & $2(1.2)$ & \\
\hline Sarcoma & $15(1.7)$ & $2(1.2)$ & \\
\hline Thyroid & $27(3.0)$ & $3(1.7)$ & \\
\hline Other specified & $40(4.5)$ & $6(3.5)$ & \\
\hline Other unknown & $123(13.9)$ & $29(16.8)$ & \\
\hline Metastasis locations, No. (\%) & & & $<.001$ \\
\hline 0 & 641 (72.3) & $92(53.2)$ & \\
\hline 1 & $157(17.7)$ & $38(22.0)$ & \\
\hline 2 & $64(7.2)$ & $28(16.2)$ & \\
\hline 3 & $23(2.6)$ & $12(6.9)$ & \\
\hline 4 & $2(0.2)$ & $3(1.7)$ & \\
\hline Complications, yes, No. (\%) & $254(28.6)$ & $67(38.7)$ & $<.001$ \\
\hline
\end{tabular}

Abbreviations: ASA, American Society of Anesthesiologists; EQ-5D, EuroQol five-dimensions questionnaire; IQR, interquartile range; KPS, Karnofsky performance score; SD, standard deviation.

Tokuhashi and Tomita categorical scores, more favorable tumor histology, and less extraspinal and visceral metastases (Table 5).

Comparison of patients who survived for at least 2 years $(\mathrm{n}=221)$ with patients who died within 2 years after surgery 


\begin{tabular}{|c|c|c|c|c|c|}
\hline \multirow[b]{2}{*}{ Variable } & \multirow[b]{2}{*}{ No. } & \multicolumn{2}{|c|}{ Unadjusted Analysis } & \multicolumn{2}{|c|}{ Multivariable Analysis } \\
\hline & & Odds Ratio $(95 \% \mathrm{Cl})$ & $P$ & Odds Ratio $(95 \% \mathrm{Cl})$ & $P$ \\
\hline Age at surgery (per 5-year increase) & 1,060 & $1.12(1.04$ to 1.20$)$ & .001 & $1.14(1.02$ to 1.27$)$ & .02 \\
\hline First surgery type (odds for emergency) & 762 & 2.06 (1.34 to 3.17$)$ & .002 & $1.20(0.67$ to 2.15$)$ & .54 \\
\hline Spinal levels affected (per additional level) & 1,060 & $1.05(0.99$ to 1.11$)$ & .11 & $1.04(0.97$ to 1.13$)$ & .27 \\
\hline Preoperative KPS (per 10-unit decrease) & 843 & 1.51 (1.36 to 1.67$)$ & $<.001$ & $1.36(1.15$ to 1.62$)$ & $<.001$ \\
\hline Preoperative EQ-5D (per unit decrease) & 730 & 7.47 (3.77 to 14.79 ) & $<.001$ & - & - \\
\hline Preoperative Frankel category & 1,038 & & $<.001$ & & .41 \\
\hline E & & Ref & & Ref & \\
\hline D & & $2.11(1.36$ to 3.28$)$ & & $1.53(0.78$ to 3.00$)$ & \\
\hline $\mathrm{A} / \mathrm{B} / \mathrm{C}$ & & $4.05(2.62$ to 6.27$)$ & & $1.55(0.73$ to 3.27$)$ & \\
\hline Tokuhashi category (surgery) & 715 & & $<.001$ & - & - \\
\hline $12-15$ & & Ref & & & \\
\hline $9-11$ & & 4.65 (1.62 to 13.34$)$ & & & \\
\hline $0-8$ & & 10.43 (3.73 to 29.14$)$ & & & \\
\hline Tomita category (surgery) & 935 & & $<.001$ & - & - \\
\hline$\leq 3$ & & Ref & & & \\
\hline $4 / 5$ & & $1.44(0.75$ to 2.75$)$ & & & \\
\hline $6 / 7$ & & $3.36(1.92$ to 5.88$)$ & & & \\
\hline$\geq 8$ & & 5.38 (3.15 to 9.19$)$ & & & \\
\hline Paralysis (odds for paralysis) & 1,060 & $2.98(2.13$ to 4.17$)$ & $<.001$ & - & - \\
\hline ASA & 850 & & .007 & - & .77 \\
\hline 1 & & Ref & & Ref & \\
\hline 2 & & 2.05 (0.89 to 4.68$)$ & & $1.06(0.42$ to 2.68$)$ & \\
\hline 3 & & $2.75(1.22$ to 6.22$)$ & & $1.10(0.43$ to 2.81$)$ & \\
\hline 4 & & $4.88(1.77$ to 13.46$)$ & & $1.93(0.48$ to 7.82$)$ & \\
\hline Complications (odds for complications) & 1,060 & $1.58(1.12$ to 2.21$)$ & .009 & 1.33 (0.79 to 2.23 ) & .28 \\
\hline
\end{tabular}

( $n=618$ ) demonstrated in univariable analysis the following factors associated with dying within 2 years after surgery: age per 5 -year increase (OR, 1.14;95\% CI, 1.07 to $1.22 ; P<.001$ ), number of affected spinal levels included in surgery per additional level (OR, 1.09; 95\% CI, 1.02 to 1.17 ; $P=.007$ ), preoperative KPS per 10-unit decrease (OR, 1.26; 95\% CI, 1.15 to 1.37; $P=.04)$, preoperative EQ-5D per unit decrease $(\mathrm{OR}, 3.74$; 95\% CI, 2.05 to $6.80 ; P<.001$ ), and preoperative Frankel and Tokuhashi and Tomita categorical scores. Table 6 gives a detailed overview of these factors. In multivariable analysis, the number of affected spinal levels included in surgery (per additional level: OR, $1.21 ; 95 \%$ CI, 1.06 to $1.38 ; P<.005)$ and primary tumor type were significant factors associated with dying in 2 years. Of all patients with one affected spinal level included in surgery, 34.9\% were alive at 2 years after surgery, whereas of all patients with two or more affected spinal levels included in surgery, $22.7 \%$ were alive at that point. Sensitivity analyses performed for both short- and longterm survival cohorts did not show any change in the significance of the results (Appendix Tables A1 and A2, online only).

\section{DISCUSSION}

In this study, preoperative factors associated with short- and longterm survival were investigated in a prospectively observed cohort of 1,266 patients who underwent surgery for treatment of symptomatic spinal metastases. Our results suggest that patients dying within 3 months after surgery were in a significantly worse physical condition preoperatively than were those who survived beyond the first 3 months, independent of unfavorable primary tumors or visceral metastases. Second, longer-term survivors were in a relatively good condition preoperatively and required surgery for only a limited number of spinal metastases, and their survival was associated with more favorable primary tumor types. Experienced clinicians may have an intuitive feel for when a patient is not a suitable candidate for surgery. Our results suggest that this intuition has a scientific basis, as the main predictor of short-term survival is functional status. KPS has previously also been shown to be a predictor of quality of life for patients who were surgically treated for spinal metastases and may therefore become a predominant prognostic variable for decision making. ${ }^{6}$

Spinal metastases are common $(\geq 70 \%)$ in patients with endstage cancer. ${ }^{12}$ Approximately $5 \%$ to $10 \%$ of patients with spinal metastases require surgical intervention as a result of mechanically unstable painful lesions and/or impending neurologic deficits. ${ }^{13}$ Clinical outcome of patients who require surgical treatment of spinal metastases depends predominantly on appropriate patient selection. This process is complex and involves the synthesis of several factors, many of which are uncertain, unreliable, or unreproducible, to determine the risk:benefit ratio of surgery. Calculation of the risk:benefit ratio is dependent upon the accuracy with which the factors involved can be determined. Unfortunately, many preoperative factors that are thought to be relevant for clinical outcome are not only difficult to quantify but also often interdependent (performance, for example, depends on the presence of neurologic deficits and/or pain) or are not yet known. As a result, some patients may not receive operative treatment, although they could have benefitted from it, whereas others 
Table 5. Descriptive Analysis of Survivors Versus Nonsurvivors at 2 Years

\begin{tabular}{|c|c|c|c|}
\hline Variable & Alive $(n=221)$ & Died $(n=618)$ & $P$ \\
\hline $\begin{array}{l}\text { Age at surgery, years, } \\
\text { mean (SD) }\end{array}$ & 57.6 (12.9) & $61.8(11.9)$ & $<.001$ \\
\hline Male, No. (\%) & 119 (53.9) & $366(59.2)$ & .17 \\
\hline First surgery type, No. (\%) & & & .001 \\
\hline Emergency & $27(14.4)$ & $87(21.4)$ & \\
\hline Scheduled & $118(62.8)$ & $187(46.0)$ & \\
\hline Urgent & $43(22.9)$ & $133(32.7)$ & \\
\hline $\begin{array}{l}\text { Spinal levels affected, median } \\
\text { (IQR) }\end{array}$ & $1(1-3)$ & $2(1-3)$ & .14 \\
\hline Preoperative KPS, mean (SD) & $64.9(21.1)$ & $55.6(19.4)$ & $<.001$ \\
\hline $\begin{array}{l}\text { Preoperative EQ-5D, median } \\
\text { (IQR) }\end{array}$ & $0.46(0.26-0.77)$ & $0.31(0.12-0.60)$ & .001 \\
\hline $\begin{array}{l}\text { Preoperative Frankel } \\
\text { category, No. (\%) }\end{array}$ & & & $<.001$ \\
\hline $\mathrm{A} / \mathrm{B} / \mathrm{C}$ & $36(16.4)$ & $186(31.0)$ & \\
\hline D & $72(32.7)$ & 215 (35.8) & \\
\hline E & $112(50.9)$ & 199 (33.2) & \\
\hline Tokuhashi score, No. (\%) & & & $<.001$ \\
\hline $0-8$ & $50(27.6)$ & $214(55.9)$ & \\
\hline $9-11$ & 86 (47.5) & 132 (34.5) & \\
\hline $12-15$ & $45(24.9)$ & $37(9.7)$ & \\
\hline Tomita score, No. (\%) & & & $<.001$ \\
\hline$\leq 3$ & $99(50.0)$ & $113(21.7)$ & \\
\hline $4 / 5$ & $44(22.2)$ & $105(20.1)$ & \\
\hline $6 / 7$ & $36(18.2)$ & $133(25.5)$ & \\
\hline$\geq 8$ & 19 (9.6) & $171(32.8)$ & \\
\hline Paralysis, yes, No. (\%) & 52 (23.5) & 209 (33.8) & .005 \\
\hline ASA, No. $(\%)$ & & & $<.001$ \\
\hline 1 & 32 (16.5) & $32(7.0)$ & \\
\hline 2 & 92 (47.4) & $182(39.7)$ & \\
\hline 3 & $68(35.1)$ & $208(45.4)$ & \\
\hline 4 & $2(1.0)$ & $36(7.9)$ & \\
\hline $\begin{array}{c}\text { Intraoperative complications, } \\
\text { yes, No. (\%) }\end{array}$ & $12(5.4)$ & $37(6.0)$ & .76 \\
\hline $\begin{array}{l}\text { Surgical complications, yes, } \\
\text { No. }(\%)\end{array}$ & 49 (22.2) & $131(21.2)$ & .76 \\
\hline $\begin{array}{l}\text { Metastatic tumor diagnosis, } \\
\text { No. (\%) }\end{array}$ & & & $<.001$ \\
\hline Breast & 56 (25.3) & 86 (13.9) & \\
\hline Colorectal & $2(0.9)$ & 39 (6.3) & \\
\hline Renal & $28(12.7)$ & $75(12.1)$ & \\
\hline Lung (any) & $19(8.6)$ & $96(15.5)$ & \\
\hline Prostate & $27(12.2)$ & $101(16.3)$ & \\
\hline Myeloma & $29(13.1)$ & $19(3.1)$ & \\
\hline Gastric & $1(0.5)$ & $15(2.4)$ & \\
\hline Liver & $2(0.9)$ & $12(1.9)$ & \\
\hline Bladder & $0(0.0)$ & $12(1.9)$ & \\
\hline Lymphoma & $5(2.3)$ & $4(0.6)$ & \\
\hline Melanoma & $6(2.7)$ & $12(1.9)$ & \\
\hline Sarcoma & $4(1.8)$ & $11(1.8)$ & \\
\hline Thyroid & $4(1.8)$ & $13(2.1)$ & \\
\hline Other specified & $1(0.5)$ & $34(5.5)$ & \\
\hline Other unknown & $37(16.7)$ & $89(14.4)$ & \\
\hline Metastasis locations, No. (\%) & & & .006 \\
\hline 0 & $164(72.2)$ & $396(64.1)$ & \\
\hline 1 & $42(19.0)$ & 119 (19.3) & \\
\hline 2 & $10(4.5)$ & $71(11.5)$ & \\
\hline 3 & $5(2.3)$ & $27(4.4)$ & \\
\hline 4 & 0 & $5(0.8)$ & \\
\hline Complications, yes, No. (\%) & 55 (24.9) & $202(32.7)$ & .031 \\
\hline
\end{tabular}

Abbreviations: ASA, American Society of Anesthesiologists; EQ-5D, EuroQol five-dimensions questionnaire; IQR, interquartile range; KPS, Karnofsky performance score; SD, standard deviation.

undergo surgery only to succumb quickly because of rapid progression of disease. To help predict survival and guide treatment in patients with metastatic spinal disease, various scoring systems have been developed. ${ }^{14-18}$ Some of these systems were designed for specific histologic tumor types, whereas others rely on general biologic tumor behavior or extent of metastatic spread to predict outcome. These scoring systems, however, do not provide information for two key questions that arise frequently in clinical practice and are strongly related with short- and long-term survival. First, will a specific patient benefit from surgical intervention or will surgery lead to accelerated systemic progression of the malignant disease and subsequent death within 3 months? Second, should the surgical procedure for this specific patient be performed with longer-term survival in mind? For example, does the patient need to achieve bony fusion of the instrumented spine segments?

With regard to deciding whether to operate for spinal metastases, several studies have shown that physicians are not consistent when given the task of estimating the life expectancy of a patient and often overestimate survival of patients with cancer. ${ }^{19}$ This overestimation may lead to the decision to perform surgery on patients who will not live long enough to benefit from the procedure. More so, the surgical procedure itself may negatively influence survival in patients with cancer to the extent that the expected remaining lifespan that was assumed preoperatively is shortened. Evidence is emerging that mechanisms of perioperative immunosuppression as a result of factors that include, but are not limited to, surgical stress and injury, anesthetic agents, and blood transfusions may impair immunosurveillance and lead to inflammatory reactions that might promote metastatic growth. ${ }^{20}$ Results of our study show that the majority of patients who died within 3 months (146 of $173 ; 84.4 \%$ ) succumbed because of rapid progression of the malignant process, rather than surgical complications. This suggests that survival may have been influenced, in part, by systemic effects of the surgical procedure and the balance between the malignant process and tumor control by immunosurveillance. ${ }^{20}$ This balance may be more delicate and easily tipped in patients with poor preoperative physical condition, as our results clearly show worse survival for patients with unfavorable preoperative parameters, including KPS, ASA, and neurologic status. In addition, it is possible that patients who are referred by oncologists for palliative spinal surgery and are estimated to have a remaining life span of approximately $\leq 6$ months will not have many chemotherapeutic options remaining to counter accelerated systemic progression of disease.

As patients undergo surgery for spinal metastases are treated in a palliative setting to improve quality of life, minimizing surgical insult is imperative. The extent and execution of the index surgery, however, should be sufficient to function as intended for the remaining life of the patient, thus avoiding any revision or repeat surgeries. For patients with longer life expectancy, performing more demanding index surgery may be preferable over less demanding, lower risk operations that may not be long-lasting and carry a higher risk of repeat surgery. The promising results of immunotherapy for tumors that were previously considered to be therapy resistant may lead to a change from tumor histology to biologic tumor behavior after treatment as the important prognostic factor for long-term survival after surgical treatment of spinal metastases. ${ }^{21}$ 
Table 6. Logistic Regression Analysis Exploring Factors Associated With Dying in 2 Years After Surgery

\begin{tabular}{|c|c|c|c|c|c|}
\hline \multirow[b]{2}{*}{ Variable } & \multirow[b]{2}{*}{ No. } & \multicolumn{2}{|c|}{ Unadjusted Analysis } & \multicolumn{2}{|c|}{ Multivariable Analysis } \\
\hline & & Odds Ratio (95\% Cl) & $P$ & Odds Ratio (95\% Cl) & $P$ \\
\hline Age at surgery (per 5-year increase) & 839 & $1.14(1.07$ to 1.22$)$ & $<.001$ & $1.01(0.99$ to 1.23$)$ & .07 \\
\hline First surgery type (odds for emergency) & 595 & $1.62(1.01$ to 2.60$)$ & .04 & $0.66(0.35$ to 1.27$)$ & .22 \\
\hline Spinal levels affected (per additional level) & 839 & 1.09 (1.02 to 1.17$)$ & .007 & $1.21(1.06$ to 1.38$)$ & .005 \\
\hline Preoperative KPS (per 10-unit decrease) & 676 & $1.26(1.15$ to 1.37$)$ & .04 & $1.13(0.97$ to 1.31$)$ & .12 \\
\hline Preoperative EQ-5D (per unit decrease) & 576 & $3.74(2.05$ to 6.80$)$ & $<.001$ & - & - \\
\hline Preoperative Frankel category & 820 & & $<.001$ & & .27 \\
\hline$E$ & & Ref & & Ref & \\
\hline $\mathrm{D}$ & & 1.68 (1.18 to 2.40$)$ & & $1.38(0.78$ to 2.47$)$ & \\
\hline $\mathrm{A} / \mathrm{B} / \mathrm{C}$ & & 2.91 (1.90 to 4.45$)$ & & $1.93(0.86$ to 4.30$)$ & \\
\hline Tokuhashi category (surgery) & 564 & & $<.001$ & - & - \\
\hline $12-15$ & & Ref & & & \\
\hline $9-11$ & & 1.87 (1.12 to 3.12$)$ & & & \\
\hline $0-8$ & & 5.21 (3.06 to 8.87$)$ & & & \\
\hline Tomita category (surgery) & 720 & & $<.001$ & - & - \\
\hline$\leq 3$ & & Ref & & & \\
\hline $4 / 5$ & & 2.09 (1.34 to 3.26$)$ & & & \\
\hline $6 / 7$ & & $3.24(2.05$ to 5.11$)$ & & & \\
\hline$\geq 8$ & & 7.88 (4.57 to 13.6$)$ & & & \\
\hline Paralysis (odds for paralysis) & 839 & 1.66 (1.17 to 2.36$)$ & .004 & - & - \\
\hline ASA & 652 & & $<.001$ & - & .76 \\
\hline 1 & & Ref & & Ref & \\
\hline 2 & & 1.98 (1.14 to 3.43$)$ & & $1.22(0.58$ to 2.57$)$ & \\
\hline 3 & & 3.06 (1.74 to 5.36$)$ & & $1.03(0.46$ to 2.28$)$ & \\
\hline 4 & & 18 (3.99 to 81.14$)$ & & $1(-)$ & \\
\hline Complications (odds for complications) & 839 & $1.47(1.03$ to 2.08$)$ & .03 & $1.22(0.70$ to 2.13$)$ & .48 \\
\hline
\end{tabular}

Abbreviations: ASA, American Society of Anesthesiologists; EQ-5D, EuroQol five-dimensions questionnaire; KPS, Karnofsky performance score; Ref, reference.

The current study shows better survival for patients who undergo surgery when still in reasonably good physical shape. Because most surgical procedures for patients with spinal metastases need to be performed in specialized centers, appropriate and timely referral is of paramount importance for good clinical outcome. ${ }^{22}$ As a general rule, patients with a malignancy in the medical history who develop back and neck pain and/or neurologic deficits have symptomatic spinal metastases until proven otherwise and require immediate work-up, including appropriate imaging of the entire spinal column. The recently developed Spinal Instability Neoplastic Score is a useful instrument to help to determine which patients should then be referred to a spine surgery service. ${ }^{23,24}$

Although our current study showed consistency over multiple preoperative domains of improved survival for fitter patients, several biases may be present. First, although each participating center provided up-to-date information on vital statistics, inaccuracies pertaining to the actual status of the patient-being dead or alive-cannot be ruled out as many patients were referred back to their own referring hospital or home physicians. As the chance of the patient being registered as alive in the database but being dead in reality is much higher than the opposite; this potential inaccuracy could have led to an overestimation of effect of the end points. Second, as baseline characteristics show, the cohort of patients was heterogeneous, with a wide range in age, tumor histology, and neurologic status at admission. The common factor for all patients was the need for surgical treatment of symptomatic spinal metastases. For each patient, indication to proceed with surgery was based on the need to decompress neural structures and/or fixate unstable spinal segments, together with sufficient fitness to endure the procedure (as assessed preoperatively by the anesthesiologist and surgeon), and a presumed life expectancy of $>3$ months (as assessed by the referring oncologist). ${ }^{8}$ All these factors can be biased by the experience and preference of the anesthesiologist, surgeon, and oncologist, institutional preference, and patient wishes. Finally, during multivariable analysis, only two factors, KPS and age, were shown to be significantly and independently associated with short-term survival, and two factors, number of affected spinal segments involved in the surgical procedure and primary tumor type, were predominant for longer-term survival. Because the results from the univariable analysis yielded many highly significant factors, the low number of significant factors in the multivariable analysis suggests a high level of interdependence of preoperative variables. For example, factors such as Frankel score and paralysis would overlap. We suggest that the plethora of significant factors in the univariable analysis, which all point in the same direction, indicate that fairly strong conclusions can be drawn from our work for the factors associated with survival in both the short term and long term.

In conclusion, results from this large prospective cohort study strongly suggest that survival depends on general preoperative fitness for palliative surgery of symptomatic spinal metastases. In particular, a low preoperative KPS is significantly and independently associated with poor short-term survival ( $<3$ months), and a limited number of spinal metastases involved in the surgical procedure and favorable primary tumor type are significantly and independently associated with longerterm survival. 


\section{AUTHORS' DISCLOSURES OF POTENTIAL CONFLICTS} OF INTEREST

Disclosures provided by the authors are available with this article at www.jco.org.

\section{AUTHOR CONTRIBUTIONS}

Conception and design: Jorrit-Jan Verlaan, David Choi, Katsuro Tomita Collection and assembly of data: David Choi, Todd Albert, Mark Arts, Laurent Balabaud, Cody Bunger, Jacob Maciej Buchowski, Chung Kee
Chung, Maarten Hubert Coppes, Hugh Alan Crockard, Bart Depreitere, Michael George Fehlings, James Harrop, Norio Kawahara, Eun Sang Kim, Chong-Suh Lee, Yee Leung, Zhongjun Liu, Antonio Martin-Benlloch, Eric Maurice Massicotte, Christian Mazel, Bernhard Meyer, Wilco Peul, Nasir A. Quraishi, Yasuaki Tokuhashi, Christian Ulbricht, Michael Wang, F. Cumhur Oner

Data analysis and interpretation: Jorrit-Jan Verlaan, David Choi, Anne Versteeg, Bernhard Meyer

Manuscript writing: All authors

Final approval of manuscript: All authors

\section{REFERENCES}

1. Rosen LS, Gordon D, Tchekmedyian NS, et al: Long-term efficacy and safety of zoledronic acid in the treatment of skeletal metastases in patients with nonsmall cell lung carcinoma and other solid tumors: A randomized, phase III, double-blind, placebocontrolled trial. Cancer 100:2613-2621, 2004

2. Jensen $A O$, Jacobsen JB, Nørgaard $M$, et al: Incidence of bone metastases and skeletal-related events in breast cancer patients: A populationbased cohort study in Denmark. BMC Cancer 11: 29, 2011

3. van der Linden YM, Lok JJ, Steenland E, et al: Single fraction radiotherapy is efficacious: A further analysis of the Dutch Bone Metastasis Study controlling for the influence of retreatment. Int J Radiat Oncol Biol Phys 59:528-537, 2004

4. Patchell RA, Tibbs PA, Regine WF, et al: Direct decompressive surgical resection in the treatment of spinal cord compression caused by metastatic cancer: A randomised trial. Lancet 366:643-648, 2005

5. Tomita K, Kawahara N, Kobayashi T, et al: Surgical strategy for spinal metastases. Spine 26: 298-306, 2001

6. Choi D, Fox Z, Albert T, et al: Prediction of quality of life and survival after surgery for symptomatic spinal metastases: A multicenter cohort study to determine suitability for surgical treatment. Neurosurgery 77:698-708, discussion 708, 2015

7. Park HY, Lee SH, Park SJ, et al: Minimally invasive option using percutaneous pedicle screw for instability of metastasis involving thoracolumbar and lumbar spine: A case series in a single center. J Korean Neurosurg Soc 57:100-107, 2015

8. Klimo P, Jr., Schmidt MH: Surgical management of spinal metastases. Oncologist 9:188-196, 2004

9. Eap C, Tardieux E, Goasgen O, et al: Tokuhashi score and other prognostic factors in 260 patients with surgery for vertebral metastases. Orthop Traumatol Surg Res 101:483-488, 2015

10. Choi D, Crockard A, Bunger $C$, et al: Review of metastatic spine tumour classification and indications for surgery: The consensus statement of the Global Spine Tumour Study Group. Eur Spine J 19:215-222, 2010

11. Global Spine Tumour Study Group: www. gstsg.org

12. Coleman RE: Clinical features of metastatic bone disease and risk of skeletal morbidity. Clin Cancer Res 12:6243s-6249s, 2006

13. Coleman RE: Skeletal complications of malignancy. Cancer 80:1588-1594, 1997 (suppl 8)

14. Westhoff PG, de Graeff A, Monninkhof EM, et al: An easy tool to predict survival in patients receiving radiation therapy for painful bone metastases. Int J Radiat Oncol Biol Phys 90:739-747, 2014

15. van der Linden YM, Dijkstra SP, Vonk EJ, et al: Prediction of survival in patients with metastases in the spinal column: Results based on a randomized trial of radiotherapy. Cancer 103: 320-328, 2005

16. Lee $\mathrm{CH}$, Chung $\mathrm{CK}$, Jahng $\mathrm{TA}$, et al: Which one is a valuable surrogate for predicting survival between Tomita and Tokuhashi scores in patients with spinal metastases? A meta-analysis for diagnostic test accuracy and individual participant data analysis. J Neurooncol 123:267-275, 2015

17. Wibmer $C$, Leithner A, Hofmann G, et al: Survival analysis of 254 patients after manifestation of spinal metastases: Evaluation of seven preoperative scoring systems. Spine 36:1977-1986, 2011

18. Bollen $L$, Wibmer $C$, Wang $M$, et al: Molecular phenotype is associated with survival in breast cancer patients with spinal bone metastases. Clin Exp Metastasis 32:1-5, 2015

19. Glare $P$, Virik K, Jones $M$, et al: A systematic review of physicians' survival predictions in terminally ill cancer patients. BMJ 327:195-198, 2003

20. Horowitz M, Neeman E, Sharon E, et al: Exploiting the critical perioperative period to improve long-term cancer outcomes. Nat Rev Clin Oncol 12: 213-226, 2015

21. Forde PM, Kelly RJ, Brahmer JR: New strategies in lung cancer: Translating immunotherapy into clinical practice. Clin Cancer Res 20:1067-1073, 2014

22. Kim $\mathrm{CH}$, Chung $\mathrm{CK}$, Jahng $\mathrm{TA}$, et al: Resumption of ambulatory status after surgery for nonambulatory patients with epidural spinal metastasis. Spine J 11:1015-1023, 2011

23. Fisher CG, DiPaola CP, Ryken TC, et al: A novel classification system for spinal instability in neoplastic disease: An evidence-based approach and expert consensus from the Spine Oncology Study Group. Spine 35:E1221-E1229, 2010

24. Fourney DR, Frangou EM, Ryken TC, et al: Spinal instability neoplastic score: An analysis of reliability and validity from the Spine Oncology Study Group. J Clin Oncol 29:3072-3077, 2011

\section{Affiliations}

Jorrit-Jan Verlaan, Anne Versteeg, and F. Cumhur Oner, University Medical Center Utrecht, Utrecht; Mark Arts, Medical Center Haaglanden, The Hague; Maarten Hubert Coppes, University Medical Center Groningen, Groningen; Wilco Peul, Leiden University Medical Centre, Leiden, the Netherlands; David Choi and Hugh Alan Crockard, The National Hospital for Neurology and Neurosurgery, University College London; Christian Ulbricht, Charing Cross Hospital, London; Yee Leung, Musgrove Park Hospital, Taunton; Nasir A. Quraishi, Queens Medical Centre, Nottingham, United Kingdom; Todd Albert and James Harrop, Thomas Jefferson University and Hospitals, Philadelphia, PA; Jacob Maciej Buchowski, Washington University, St. Louis, MO; Michael Wang, Jackson Memorial Hospital, University of Miami, Miami, FL; Laurent Balabaud and Christian Mazel, L'Institut Mutualiste Montsouris, Paris, France; Cody Bunger, University Hospital of Aarhus, Aarhus, Denmark; Chung Kee Chung, Seoul National University; Eun Sang Kim and Chong-Suh Lee, Samsung Medical Center, Sungkyunkwan University School of Medicine, Seoul, South Korea; Bart Depreitere, University Hospital Leuven, Leuven, Belgium; Michael George Fehlings and Eric Maurice Massicotte, Toronto Western Hospital, Toronto, ON, Canada; Norio Kawahara, Kanazawa Medical University Hospital; Katsuro Tomita, Kanazawa University, Kanazawa; Yasuaki Tokuhashi, Nihon University School of Medicine, Tokyo, Japan; Zhongjun Liu, Peking University Hospital, Beijing, People's Republic of China; Antonio MartinBenlloch, Hospital Universitario Dr Peset, Valencia, Spain; and Bernhard Meyer, Technical University of Munich, Munich, Germany. 
Characteristics of Patients Who Survived < 3 Months or $>2$ Years After Surgery for Spinal Metastases: Can We Avoid Inappropriate Patient Selection?

The following represents disclosure information provided by authors of this manuscript. All relationships are considered compensated. Relationships are self-held unless noted. I = Immediate Family Member, Inst = My Institution. Relationships may not relate to the subject matter of this manuscript. For more information about ASCO's conflict of interest policy, please refer to www.asco.org/rwc or jco.ascopubs.org/site/ifc.

Jorrit-Jan Verlaan

No relationship to disclose

David Choi

Research Funding: DePuy Synthes (Inst)

Anne Versteeg

No relationship to disclose

Todd Albert

Employment: DePuy Synthes

Stock or Other Ownership: Paradigm Spine

Consulting or Advisory Role: DePuy Synthes

Patents, Royalties, Other Intellectual Property: Royalties from DePuy

Synthes, royalties from Biomet Spine

Mark Arts

Consulting or Advisory Role: InSpine, Biomet, Silony, Amedica, EIT, QMediq

Research Funding: Zimmer Biomet (Inst), EIT (Inst), Intrinsics (Inst)

Patents, Royalties, Other Intellectual Property: EIT, Silony

Travel, Accommodations, Expenses: Amedica

Laurent Balabaud

No relationship to disclose

\section{Cody Bunger}

No relationship to disclose

Jacob Maciej Buchowski

Consulting or Advisory Role: Advance Medical, Corelink, DePuy Synthes, Gerson Lehrman Group, Globus Medical, K2M, Medtronic, Stryker Speakers' Bureau: Broadwater, Vertical Health, DePuy Synthes, Globus Medical, Orthofix, Stryker

Patents, Royalties, Other Intellectual Property: Wolters Kluwer, Globus Medical

Expert Testimony: Various entities

Other Relationship: AO Foundation (parent organization to AO Spine)

Chung Kee Chung

No relationship to disclose

Maarten Hubert Coppes

No relationship to disclose

Hugh Alan Crockard

No relationship to disclose

Bart Depreitere

Research Funding: Johnson \& Johnson

Michael George Fehlings

No relationship to disclose

James Harrop

Consulting or Advisory Role: DePuy Synthes, Bioventus

Norio Kawahara

No relationship to disclose

\section{Eun Sang Kim}

Honoraria: Takeda Pharmaceuticals, Hanmi Medicare

Research Funding: Yuhan Corporation (Inst)

Travel, Accommodations, Expenses: B. Braun Medical

\section{Chong-Suh Lee}

No relationship to disclose

Yee Leung

No relationship to disclose

\section{Zhongjun Liu}

No relationship to disclose

Antonio Martin-Benlloch

No relationship to disclose

Eric Maurice Massicotte

Honoraria: AO Spine

Christian Mazel

Stock or Other Ownership: Amplitude

Honoraria: Medtronic, AO Spine, Zimmer Spine, DePuy Synthes

Consulting or Advisory Role: Clariance, AO Spine

Travel, Accommodations, Expenses: DePuy Synthes, Medtronic,

Clariance, Zimmer Spine

\section{Bernhard Meyer}

Honoraria: Medtronic, DePuy Synthes, BrainLAB, Ulrich Medical Consulting or Advisory Role: Ulrich Medical, Spineart

Research Funding: Ulrich Medical (Inst), Medtronic (Inst), Relivant (Inst)

Travel, Accommodations, Expenses: Medtronic, DePuy Synthes

\section{Wilco Peul}

Research Funding: Medtronic (Inst), Paradigm (Inst), Aesculap (Inst)

\section{Nasir A. Quraishi}

Honoraria: AO Spine, Medtronic, DePuy Synthes

Research Funding: Medtronic (Inst), Depuy Synthes (Inst)

Travel, Accommodations, Expenses: AO Spine, Medtronic

Yasuaki Tokuhashi

No relationship to disclose

Katsuro Tomita

No relationship to disclose

Christian Ulbricht

No relationship to disclose

Michael Wang

No relationship to disclose

F. Cumhur Oner

Research Funding: DePuy Synthes (Inst)

Travel, Accommodations, Expenses: AO Spine 


\section{Appendix}

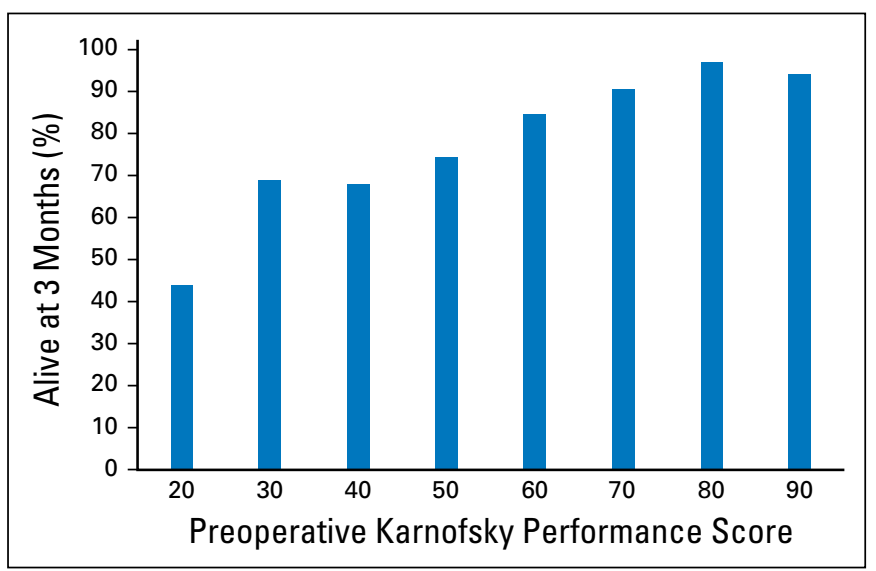

Fig A1. Relation between preoperative Karnofsky performance score and poor survival.

Table A1. Sensitivity Analysis of Multivariable Logistic Regression Model of Table 4

\begin{tabular}{|c|c|c|c|c|}
\hline \multirow[b]{2}{*}{ Variable } & \multicolumn{2}{|c|}{ Missing Patients Coded as Having Died } & \multicolumn{2}{|c|}{ Missing Patients Coded as Being Alive } \\
\hline & Odds Ratio (95\% Cl) & $P$ & Odds Ratio (95\% Cl) & $P$ \\
\hline Age at surgery (per 5-year increase) & $1.13(1.04$ to 1.22$)$ & .002 & $1.11(1.00$ to 1.23$)$ & .05 \\
\hline First surgery type (odds for emergency) & $0.84(0.53$ to 1.32$)$ & .44 & $1.30(0.74$ to 2.30$)$ & .36 \\
\hline Spinal levels affected (per additional level) & $1.01(0.94$ to 1.08$)$ & .89 & $1.05(0.97$ to 1.14$)$ & .19 \\
\hline Preoperative KPS (per 10-unit decrease) & $1.13(1.01$ to 1.26$)$ & .04 & $1.37(1.16$ to 1.61$)$ & $<.001$ \\
\hline Preoperative Frankel category & & .04 & & .65 \\
\hline$E$ & Ref & & Ref & \\
\hline $\mathrm{D}$ & 1.56 (0.99 to 2.56$)$ & & $1.35(0.70$ to 2.62$)$ & \\
\hline $\mathrm{A} / \mathrm{B} / \mathrm{C}$ & 1.96 (1.14 to 3.37$)$ & & 1.33 (0.64 to 2.76$)$ & \\
\hline ASA & & .51 & & .65 \\
\hline 1 & Ref & & Ref & \\
\hline 2 & $1.13(0.63$ to 2.03$)$ & & 1.09 (0.44 to 2.75$)$ & \\
\hline 3 & 0.85 (0.46 to 1.59$)$ & & $1.21(0.48$ to 3.07$)$ & \\
\hline 4 & $1.27(0.43$ to 3.72$)$ & & $2.17(0.57$ to 8.29$)$ & \\
\hline Complications (odds for complications) & $1.00(0.68$ to 1.45$)$ & .98 & $1.41(0.85$ to 2.33$)$ & .18 \\
\hline
\end{tabular}


Verlaan et al

Table A2. Sensitivity Analysis of Multivariable Logistic Regression Model of Table 6

\begin{tabular}{|c|c|c|c|c|}
\hline \multirow[b]{2}{*}{ Variable } & \multicolumn{2}{|c|}{ Missing Patients Coded as Having Died } & \multicolumn{2}{|c|}{ Missing Patients Coded as Being Alive } \\
\hline & Odds Ratio $(95 \% \mathrm{Cl})$ & $P$ & Odds Ratio $(95 \% \mathrm{Cl})$ & $P$ \\
\hline Age at surgery (per 5-year increase) & $1.08(0.99$ to 1.18$)$ & .08 & $1.04(0.96$ to 1.12$)$ & .32 \\
\hline First surgery type (odds for emergency) & $0.84(0.49$ to 1.46$)$ & .54 & $0.70(0.45$ to 1.11$)$ & .13 \\
\hline Spinal levels affected (per additional level) & $1.13(1.01$ to 1.27$)$ & .03 & $1.18(1.08$ to 1.30$)$ & $<.001$ \\
\hline Preoperative KPS (per 10-unit decrease) & 1.07 (1.01 to 1.83$)$ & .05 & $1.12(1.00$ to 1.25$)$ & .06 \\
\hline Preoperative Frankel category & & .35 & & .84 \\
\hline$E$ & Ref & & Ref & \\
\hline $\mathrm{D}$ & 1.22 (0.73 to 2.03$)$ & & 1.06 (0.68 to 1.65$)$ & \\
\hline$A / B / C$ & $1.68(0.83$ to 3.37$)$ & & $1.18(0.68$ to 2.04$)$ & \\
\hline ASA & & .71 & & .46 \\
\hline 1 & Ref & & Ref & \\
\hline 2 & $0.85(0.46$ to 1.58$)$ & & 1.25 (0.71 to 2.19$)$ & \\
\hline 3 & $0.75(0.38$ to 1.49$)$ & & 1.37 (0.75 to 2.48$)$ & \\
\hline 4 & $1(-)$ & & $2.61(0.76$ to 8.94$)$ & \\
\hline Complications (odds for complications) & $1.12(0.70$ to 1.80$)$ & .64 & 1.29 (0.88 to 1.89$)$ & .19 \\
\hline
\end{tabular}

Abbreviations: ASA, American Society of Anesthesiologists; KPS, Karnofsky performance score; Ref, reference. 